Research Article

\title{
Interactive Buckling of Q420 Welded Circular Tubes under Axial Compression
}

\author{
Bin Huang $\mathbb{D}^{1}$ and Zhou Che Hong ${ }^{2}$ \\ ${ }^{1}$ Nanjing Institute of Technology, Nanjing, China \\ ${ }^{2}$ China Shipbuilding NDRI Engineering Co., Ltd., Shanghai, China \\ Correspondence should be addressed to Bin Huang; 89690966@qq.com
}

Received 12 March 2020; Revised 25 May 2020; Accepted 19 June 2020; Published 16 July 2020

Academic Editor: Guoqiang Xie

Copyright (C) 2020 Bin Huang and Zhou Che Hong. This is an open access article distributed under the Creative Commons Attribution License, which permits unrestricted use, distribution, and reproduction in any medium, provided the original work is properly cited.

\begin{abstract}
Finite element models (FE models) of high-strength steel Q420 (yield strength $420 \mathrm{MPa}$ ) circular tubes considering residual stresses and local and overall geometric imperfections were established and verified against existing test data. Based on parameter analysis, it was derived that the reduction of ultimate capacity resulting from residual stresses was up to $11.8 \%$. When slenderness ratio was larger than 25 , the effect of overall geometric imperfection played a major role compared with that of local geometric imperfection, which resulted in the reduction of the ultimate capacity of about $11.5 \%$. Through tracking the failure process, it was found that, in the initial stage of loading, the deformation of columns mainly presents overall bending. When the load increased near the ultimate load, local buckling occurred and the bearing capacity decreased rapidly. The $D / t$ limit value 27 was determined for preventing the local buckling, and the overall slenderness $\lambda_{l}$ limit value 40 was proposed to distinguish whether local buckling occurs. Based on the FEM result and test data, the applicability of ASCE48-05 and AS4100 for local buckling resistance was evaluated. Continuing the result of stub columns, curve a in GB50017-2017 and in Eurocode 3 of the overall buckling factor $\varphi$ was proposed to be used in EWM and DSM for estimating the interactive buckling resistance of circular tubes of Q420 under axial compression.
\end{abstract}

\section{Introduction}

With the improvement of steel-making technology, highstrength steel is popularized which also expedites the use of high-strength steel circular tubes gradually in the transmission tower structure. Under axial compression, sectional strength failure, local bucking, overall buckling, and localoverall coupling buckling (hereinafter referred to as "interactive buckling") are the most basic failure forms of circular tubes. The slenderness ratio of circular tubes in transmission towers is usually between 35 and 55, where interactive buckling is more prone to be triggered, which was proved by the test data published by Shi et al. [1]. Newly issued Chinese steel structure code (GB50017-2017) [2] has taken the steel material Q420 into account, and the limit ratio of diameter to thickness $(D / t)$ preventing local buckling is provided for the circular tubes, whereas the countermeasures are not clearly specified to meet the case of $D / t$ out of the limit value, which may be common in transmission tower structures or offshore structures. So far, the research on the circular tube has achieved fruitful achievement. For the research of local buckling, more theoretical achievements of stub cylindrical shell provide a significant reference for analytical solution $[3,4]$. Furthermore, Zhao et al. $[5,6]$ shared an important experimental experience for the study of local buckling of ultrahigh strength circular tube with a yield strength of $1350 \mathrm{MPa}$. For the research on overall buckling, in 2014, Shi et al. [1] carried out the test research on the overall buckling performance of a welded circular tube with a yield strength of $420 \mathrm{MPa}$ (Q420). As for the local-overall interactive buckling performance of a welded circular tube, in 1988, the limit value of $D / t$ of the local buckling and the slenderness ratio $\lambda_{l}$ of the overall buckling were proposed based on axial compression 
test by Shen et al. [7]. In addition, research on initial imperfections such as residual stresses closely related to buckling performance has also attracted the attention of scholars, which can be traced back to 1976 [8] and 1977 [9] and furtherly enriched [10-13] for higher-strength steel in recent years. Although related researches have been published earlier, more attention is needed for the study of the interactive buckling performance of high-strength steel welded circular tubes. In terms of a number of experimental programs of high-strength steel circular tubes concentrating on the local buckling and the overall buckling singly, the research on the local-overall interactive buckling was uncustomary for circular tubes. In this work, the FE models for Q420 welded circular tubes validated through existing experiment data were used to explore the influencing factors and estimation approach of interactive buckling resistance.

\section{Finite Element Model}

For the circular tube stub columns, the ratio of diameter to thickness $(D / t)$ is the main factor focused on to mount the reduction of the section strength resulting from local buckling. And for the long column, the overall slenderness ratio $\left(\lambda_{l}\right)$ is the indicator for the overall buckling resistant. As for the FE specimens designed for the research of the ultimate capacity of intermediate length circular tubes, both $D / t$ and $\lambda_{l}$ were comprehensively taken into account because of the local and overall buckling coupled. The geometric characteristics of the finite element models (FE models) were presented as shown in Table 1 . These FE models consist of 8 cross-section types. The $D / t$ of cross sections varies from 22 to 76 , and the overall slenderness ratio $\lambda$ varies from 15 to 60 , totaling 80 pieces. Geometrical and material nonlinearities were incorporated in the FE models in order to replicate the structural behavior observed in the experimental program.

2.1. Type of Element and Element Mesh Size. Shell elements SHELL181 provided by general-purpose finite element analysis (FEA) package ANSYS were adopted to discretize the high-strength Q420 welded circular tube columns to capture the local deformation and stress distribution, which have been successfully implemented in some studies [14].

Suitable element size can balance the multipoint requirements of numerical calculation including calculation accuracy, efficiency, and convergence of the numerical calculation. In this paper, the welded residual stresses were simulated by applying initial stresses directly at the gauss integral points. The tube circumference line was discretized into 20 elements and the number of element in axis direction was 20 times the ratio of the axis length to the circumference length. In this way, each element was basically square and with the same element number, which brought convenience to automatic batch calculation.

2.2. Boundary Condition and Loading Method. The specimens were usually hinged in two ends in most experiments for the research of the overall buckling or the interactive buckling performance as shown in Figure 1. The boundary conditions for all FE models were simulated according to the test conditions. The details are described as follows. Because the element mass was not considered in the static analysis, at the midpoint of the two-end surfaces of the specimen, the mass element (Mass 21) was set as the main node to form a rigid surface with the nodes of the circumference through the "CERIG" command shown in Figure 2. Translations in the $x, y$, and $z$ directions of the mass element in one end were constrained, and translations in the $x$ and $y$ directions of the mass element in another end were constrained, where pressure loads were applied in $z$ direction simultaneously.

2.3. Material Properties. Because the material mechanical characteristics are random variables which are not completely consistent even for the steel of the same grade, in order to ensure the universality of the investigation results, the data put into practice in numerical simulation of high-strength steel columns in [15] were adopted. The stress-strain relation employed in FEM was the multilinear kinematic hardening model with a yield strength of $420 \mathrm{MPa}$, a Young modulus of $210 \mathrm{GPa}$, and a Poisson ratio of 0.3 as shown in Figure 3 . The strain $\varepsilon_{\text {st }}$ denotes the strain corresponding to the end of the yield plateau, and the strain $\varepsilon_{\mathrm{u}}$ corresponds to the strain at the steel ultimate tensile stress $f_{\mathrm{u}}$.

2.4. Geometric Imperfection. Two types of imperfections, including local geometric imperfections and overall geometric imperfections, were both taken into account. The overall geometric imperfection amplitude was usually $L /$ 1000, including the initial bending of the whole member and the initial eccentricity in the actual loading. The initial local geometric imperfection of tubular section members mainly depends on the $D / t$. Various amplitude specifications are provided in different regions, such as $(w / t)=(1 / 16.5) \sqrt{r / t}$ in AISC, $(w / t)=(1 / 12) \sqrt{r / t}$ in ECCS, and $w / t=$ $(1 / 1390)^{3} \sqrt{r / t}$ in ESDC, respectively. In comparison, it can be seen that provisions in ECCS correspond to the largest amplitude. For example, the amplitude value of $\mathrm{D} 480 \times 12$ is $4.60 \mathrm{~mm}, 6.32 \mathrm{~mm}$, and $0.002 \mathrm{~mm}$, respectively. In the subsequent FE analysis, the amplitude "ECCS" was adopted.

The details of the operation steps of ANSYS to introduce both overall and local geometric imperfections into FE models were as follows. The linear buckling mode shape was used to create an initial geometric imperfection for the nonlinear postbuckling analysis. The first buckling mode was adopted to update coordinates with the "UPGEOM" command provided by ANSYS program. Through adjusting the thickness of circular tubes, the overall buckling modes can be obtained, as shown in Table 2, and then the FE model node coordinates were updated. Subsequently, the thickness was adjusted back to the original thickness and the linear buckling analysis was repeated to update the node coordinates again with local buckling mode. Finally, the two kinds of geometric imperfection shapes are superposed by each other, as shown in Figure 4. 
TABLE 1: Finite element analysis specimens.

\begin{tabular}{lccccc}
\hline $\begin{array}{l}\text { FEM specimen } \\
\text { label }\end{array}$ & $\begin{array}{c}\text { Outer diameter } \\
(\mathrm{mm})\end{array}$ & $\begin{array}{c}\text { Thickness } \\
(\mathrm{mm})\end{array}$ & $\begin{array}{c}\text { Diameter-thickness } \\
\text { ratio } D / t\end{array}$ & $\begin{array}{c}\text { Slenderness } \\
\text { ratio } \lambda\end{array}$ & $\begin{array}{c}\text { Nondimensional slenderness ratio } \\
\lambda_{n}=(\lambda / \pi) \sqrt{f_{y} / E}\end{array}$ \\
\hline $\mathrm{D} 89 \times 4$ & 89 & 4 & 22 & & \\
$\mathrm{D} 159 \times 6$ & 159 & 6 & 27 & & \\
$\mathrm{D} 194 \times 6$ & 194 & 6 & 32 & $15,20,25,30,35$ & $0.216 \sim 0.862$ \\
$\mathrm{D} 480 \times 12$ & 480 & 12 & 40 & $40,45,50,55,60$ & \\
$\mathrm{D} 273 \times 6$ & 273 & 6 & 46 & & \\
$\mathrm{D} 426 \times 8$ & 426 & 8 & 53 & & \\
$\mathrm{D} 508 \times 8$ & 508 & 8 & 64 & & \\
$\mathrm{D} 610 \times 8$ & 610 & 8 & 76 & & \\
\hline
\end{tabular}

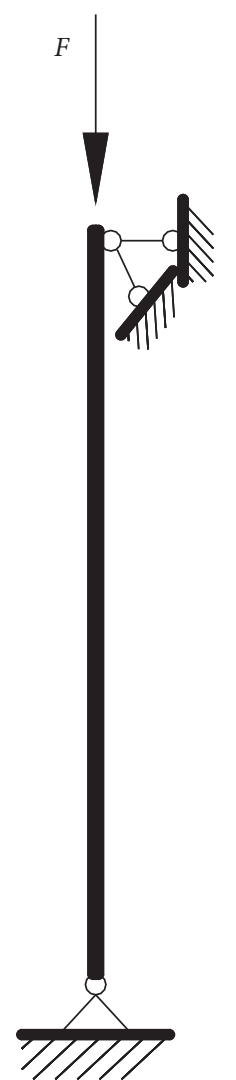

FiguRe 1: Specimen boundary conditions.

2.5. Longitudinal Residual Stress Distribution. Residual stresses are unavoidable for welded members, and relevant researches have been carried out by many scholars as introduced in Section 1. From the research in [1], it can be obtained that the longitudinal residual stress distribution result from submerged arc welding is not uniform for different steel grades and uneven along tube thickness direction (Figure 5). Simplified mode of longitudinal residual stresses of Q420 circular tubes measured in [1] was given out and introduced in the FE models with SHELL181 to verify the application, the details of which were as follows: two layers along the thickness direction of shell element were set up with only one integration point in each layer and the residual stresses were applied at integral points of different layers as shown in Figure 6, which were also adopted in this paper.
The residual stresses were applied to columns as a load rather than load effect, so after the introduction of residual stresses at the integration points, iterative solution of nonlinear equations was carried out, which caused slight disparity (up to $2 \%$ ) of the distribution of residual stresses as shown in Figure 5, where "I-Q420-inner" represented the residual stresses initially input on the inner surface and "OQ420-inner" represented the residual stresses after iterative computation.

\section{Existing Test Results and FE Model Verification}

Validation of FEMs was conducted through comparing FE model results with existing experiment data including failure cases of local buckling, interactive buckling, and overall buckling. The buckling resistances of FE models, $N_{\text {FEM }}$, and the buckling resistances of test specimens, $N_{\text {test }}$, are compared in Table 3, where it can be found that most of the result of FEM was smaller than test data. The reason was that, due to the residual stress distribution model published in [1] arranged along the full length of the member, the numerical results may be excessively reduced leading to underestimating of the bearing capacity. The inference was further tested in subsequent sections. On the whole, the average value of the ratio of the finite element calculation results to the test results was 0.957 , and the standard deviation was $3.34 \%$. Therefore, it is reasonable to believe that the FE models in this paper can ensure the accuracy of the subsequent numerical results. The failure mode of FE models was compared with that published in [1] as shown in Figure 7. Figure 7(a) shows a typical overall buckling mode of test specimen compared with FE model using beam element in [1] and using shell element in this work. Figure 7(b) shows the interactive buckling mode comparison of the test specimen and the FE model using shell element in this work.

\section{Numerical Results}

4.1. Parametric Studies. The validated FE models were used herein to carry out systematic parametric studies and reveal the influences of the parameters, including the residual stresses, the initial local and overall geometric imperfections, $D / t$ limit for local buckling, and the overall slenderness ratio $\lambda$. 


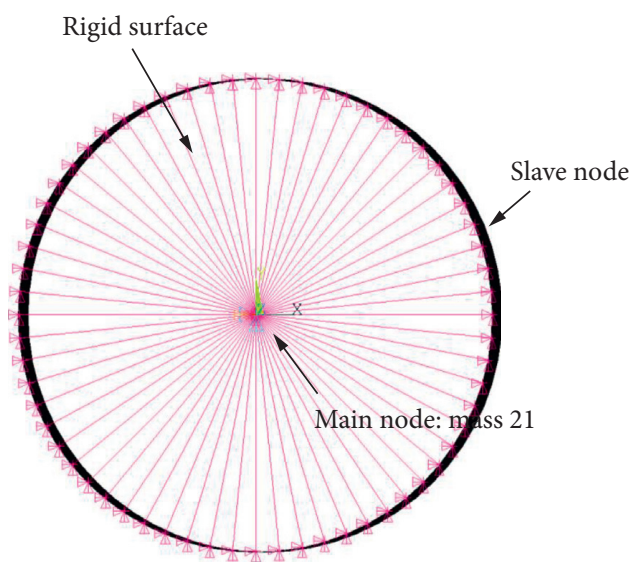

Figure 2: End of specimen setup.

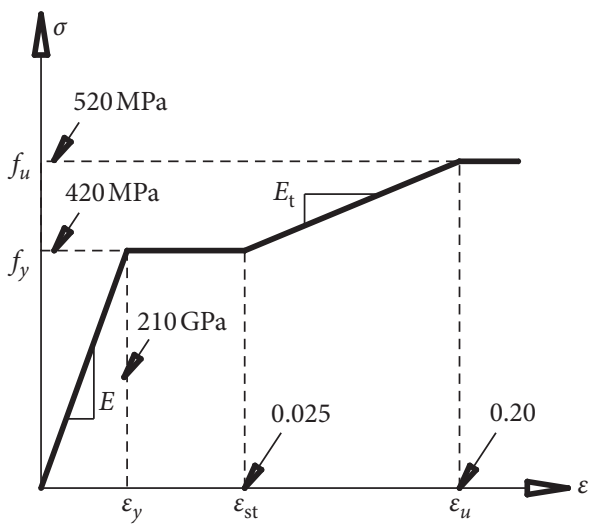

FIGURE 3: Stress-strain relationship of steel for FEA models.

TABle 2: Effect of section thickness on buckling modal.

$t$

" $t$ " is tube thickness.

4.1.1. Analysis of Welding Residual Stress Effect. Two types of cross sections are as follows: D $159 \times 6$ and D508 $\times 8$ were selected for the analysis of the influence of residual stresses. Two cases were compared to investigate the residual stress effect, one of which was only geometric imperfections considered, and the other one was geometric imperfections and residual stresses considered comprehensively. The details were as shown in Figure 8, where it can be seen that, with the increase of $\lambda$, the residual stress effect tends to be significant. Due to the influence of difference of local half wave number and length of geometric imperfection, some individual points showed particularity, such as $\lambda=40$, and the residual stress effect was the least. When $\lambda=60$, the disparity was up to $11.8 \%$. In addition, the effect of residual stresses on the overall buckling factor $\varphi$ was investigated as shown in Table 4, where

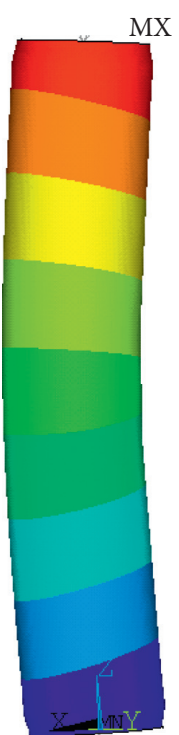

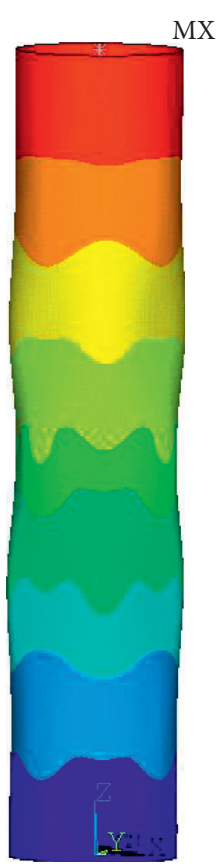

(b)

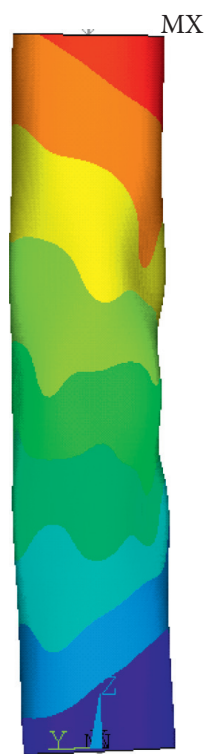

(c)
Figure 4: Global and local geometry imperfection. (a) Deformation of FE models introduced overall imperfection. (b) Deformation of FE models introduced local imperfection. (c) Deformation of FE models introduced overall and local imperfection.

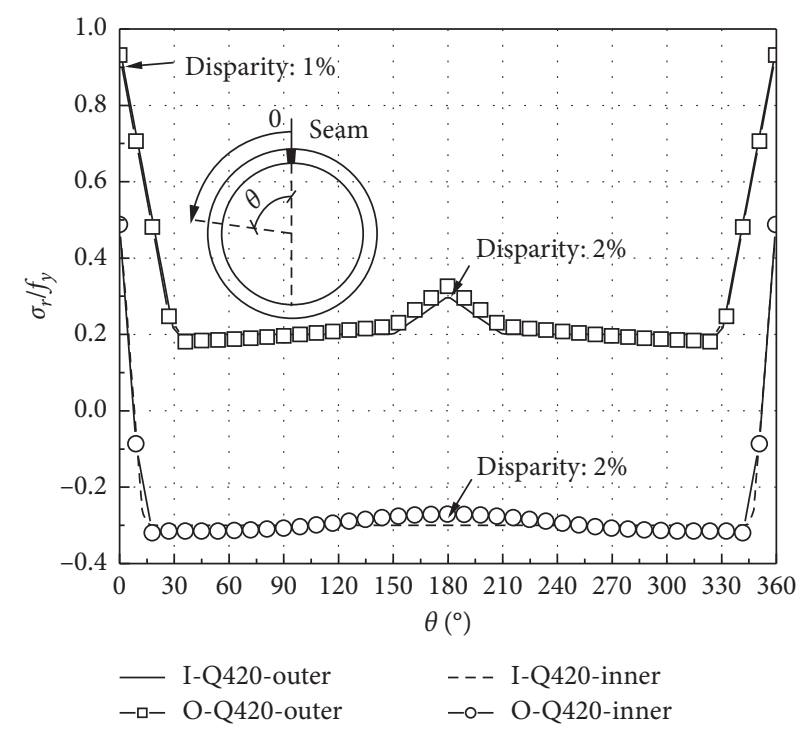

FIGURE 5: Residual stresses distribution of Q420 welded tubes [10].

it can be seen that the reduction $\varphi$ was up to around $12 \%$ and increased resulting from larger slenderness $\lambda$.

Furthermore, in Section 3, it was mentioned that the ultimate capacity of circular tubes with a large slenderness ratio may be underestimated when taking the residual stresses obtained from the stub column test into account along the whole component. In order to further prove this inference, the amplitude of residual stress mode in [1] was reduced to $20 \%$ of the original value, and the effect was compared with 

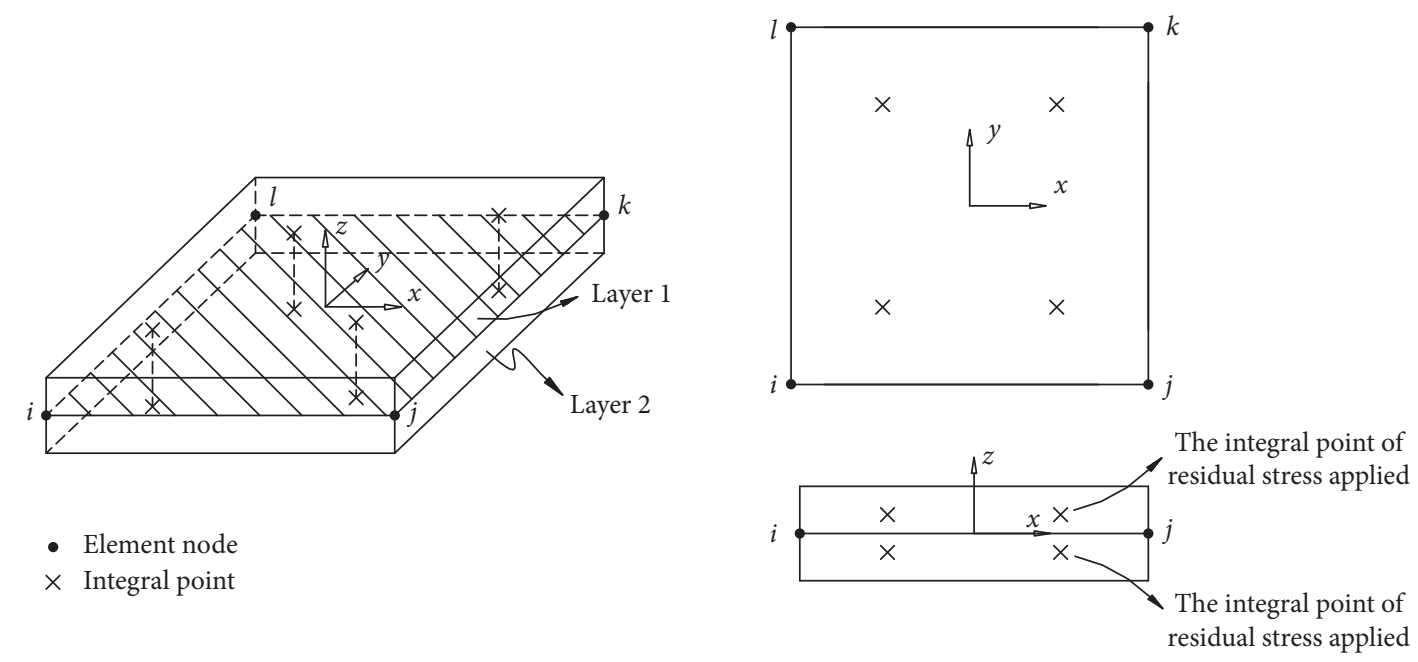

Figure 6: Integral point arrangement.

TABle 3: Comparison of FEA results and experimental results.

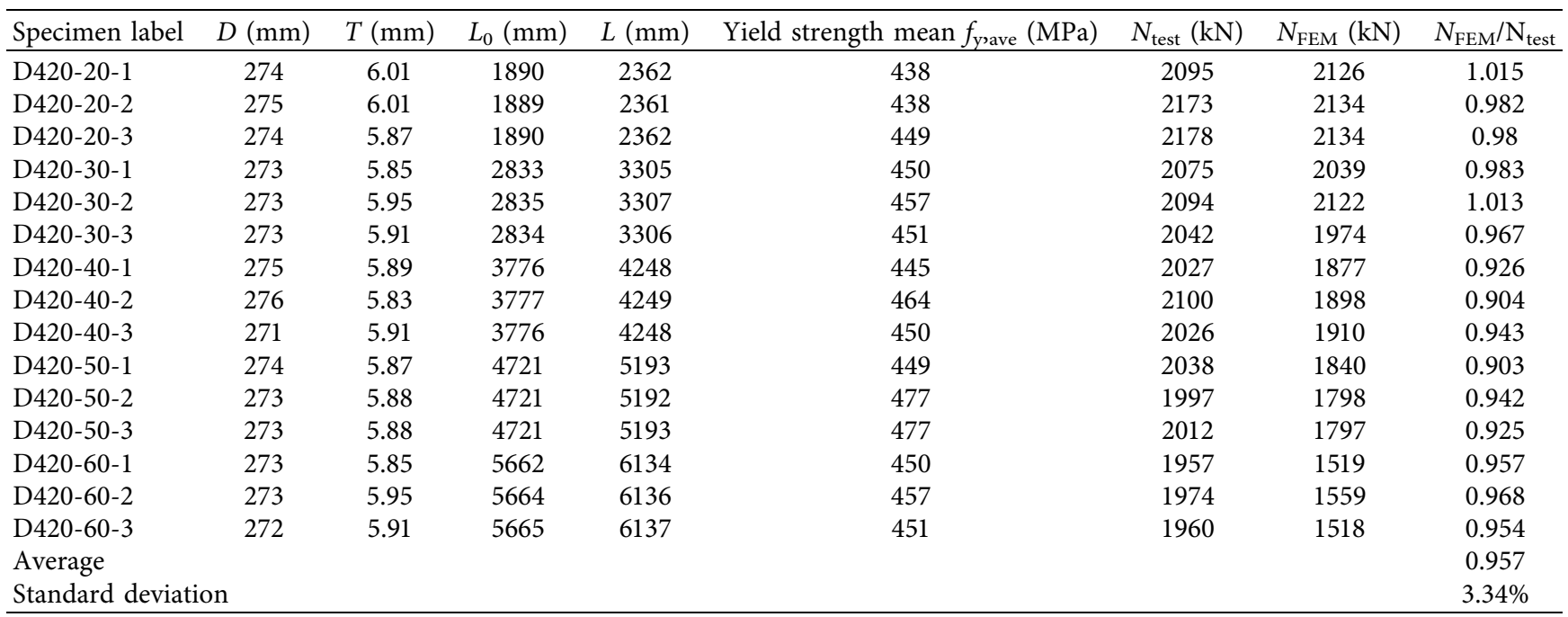

test data as shown in Figure 9. It can be obtained that the increase of residual stress amplitude led to a larger reduction of ultimate capacity which was more prominent especially for large slenderness ratio members, but not in proportion. For example, for $\lambda=50$, although the residual stresses were reduced to $20 \%$, the bearing capacity was increased to $10 \%$.

The load versus axial compression displacement $U_{z}$ of sections D $159 \times 6$ and D $508 \times 8$ whether residual stress was considered is depicted in Figure 10, where it can be seen that the ultimate capacity of columns was reduced by $5.91 \%$ and $11.8 \%$ for $\mathrm{D} 159 \times 6$ and $\mathrm{D} 508 \times 8$, respectively, due to residual stresses, but the initial stiffness of columns was influenced slightly mainly because the material was still in the elastic stage. When the applied load exceeded $60 \%$ of $N_{y}$ $\left(N_{y}=f_{y} A\right)$, the column stiffness began to decline. In order to quantitatively evaluate the influence of residual stresses on the stiffness of columns, the secant stiffness was defined with the slope of the line connecting the local buckling point and the origin on the curve of load versus axial compression displacement $U_{z}$ as shown in Figure 10, which was dropped by $5.2 \%$ and $4.1 \%$ resulting from the residual stresses.

4.1.2. Analysis of Geometric Imperfection Effect. In this section, the influence of overall and local geometric imperfections on ultimate capacity was focused on. Sections D $159 \times 6$ and $\mathrm{D} 508 \times 8$ were still selected for relevant analysis and comparison. The form and arrangement of geometric imperfections were described in Section 2. The FE model results are shown in Figure 11, from which the following conclusion can be drawn: from the overall trend, the impact of overall imperfection was up to $7.4 \%, 11.5 \%$, which was $4.4 \%$ and $3.7 \%$ larger than local geometric imperfections for $\mathrm{D} 159 \times 6$ and $\mathrm{D} 508 \times 8$, respectively. With the increase of slenderness ratio, the effect of overall geometric imperfection on ultimate capacity became more prominent. 

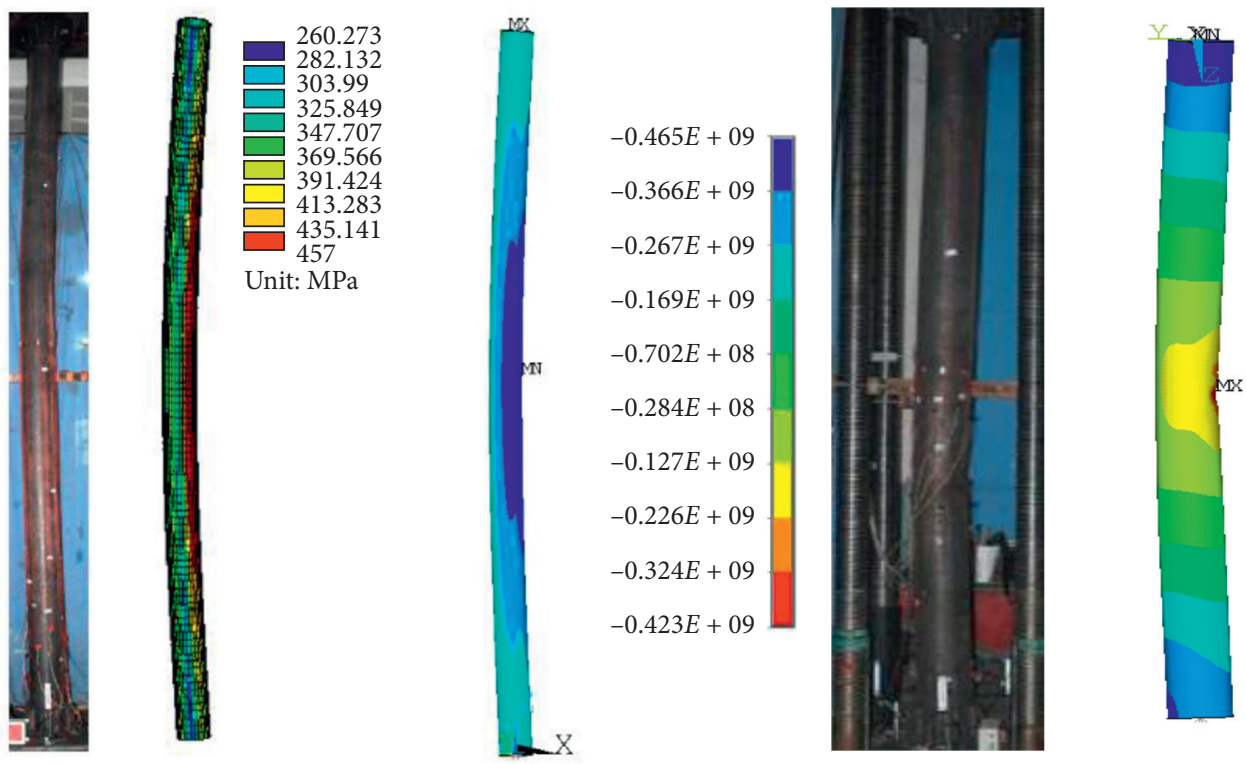

(a)

(b)

FIGURE 7: Failure mode comparison of FEA results and experimental results. (a) The overall buckling mode of specimen $(\lambda=60)$ in [1]. (b) The interactive buckling mode of specimen $(\lambda=40)$ in [1].

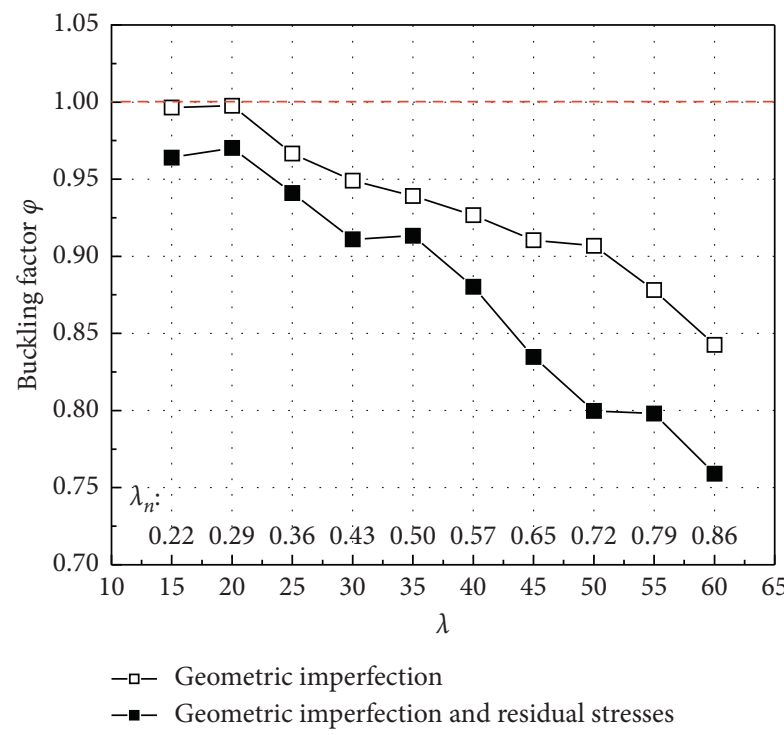

(a)

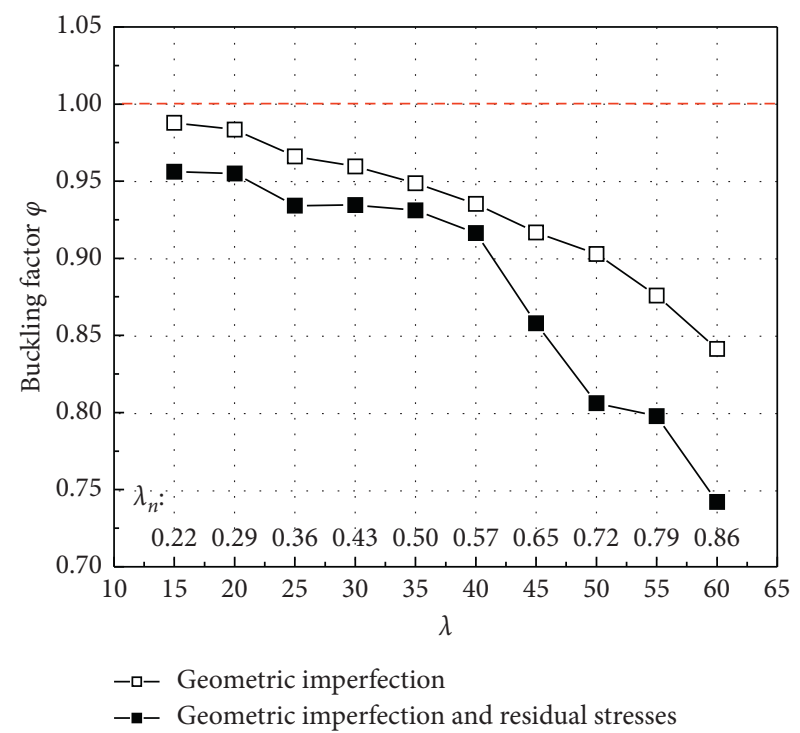

(b)

Figure 8: Comparison of the influence of residual stresses. (a) D159 $\times 6$. (b) D508 $\times 8$.

TABLE 4: Effect of residual stresses on overall buckling factor $\varphi$.

\begin{tabular}{lccccc}
\hline \multirow{2}{*}{ FEM } & \multicolumn{5}{c}{ Slenderness ratio $\lambda$} \\
& $20(\%)$ & $30(\%)$ & $40(\%)$ & $50(\%)$ & $60(\%)$ \\
\hline D159 $\times 6$ & 1.21 & 2.94 & 5.91 & 9.53 & 12.0 \\
D508 $\times 8$ & 1.90 & 3.22 & 5.46 & 9.46 & 13.0 \\
\hline
\end{tabular}

Considering the influence of different geometric imperfection, the load and axial compression deformation $\left(U_{\mathrm{x}}\right)$ curves of members are shown in Figure 12, where it can be found that, under the influence of local geometric imperfections, the ultimate capacity of the component decreased slowly after reaching its maximum value (mostly up to the yield strength), showing certain ductile failure 


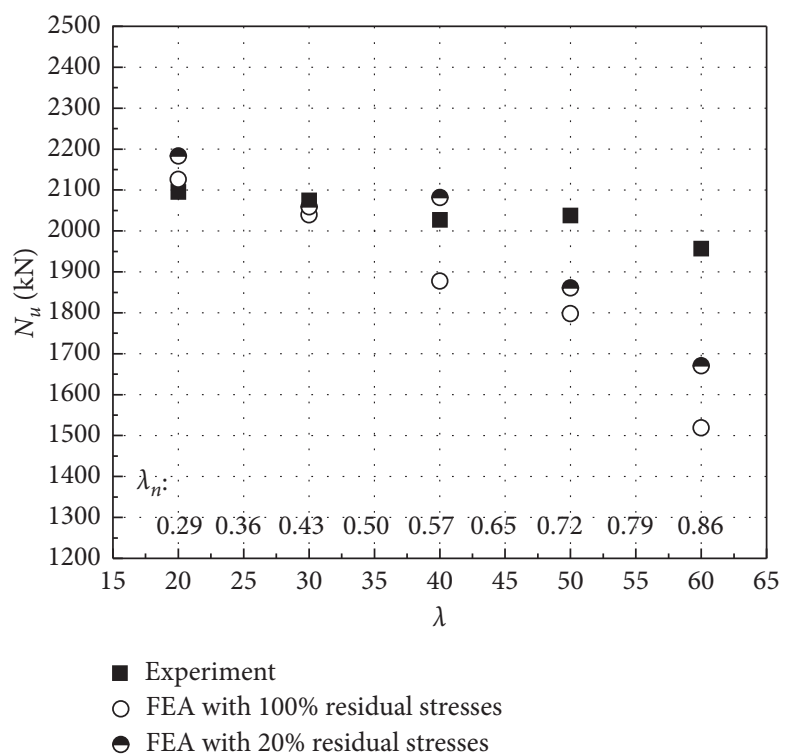

FIGURE 9: Comparison of axial load capacity with different residual stresses.

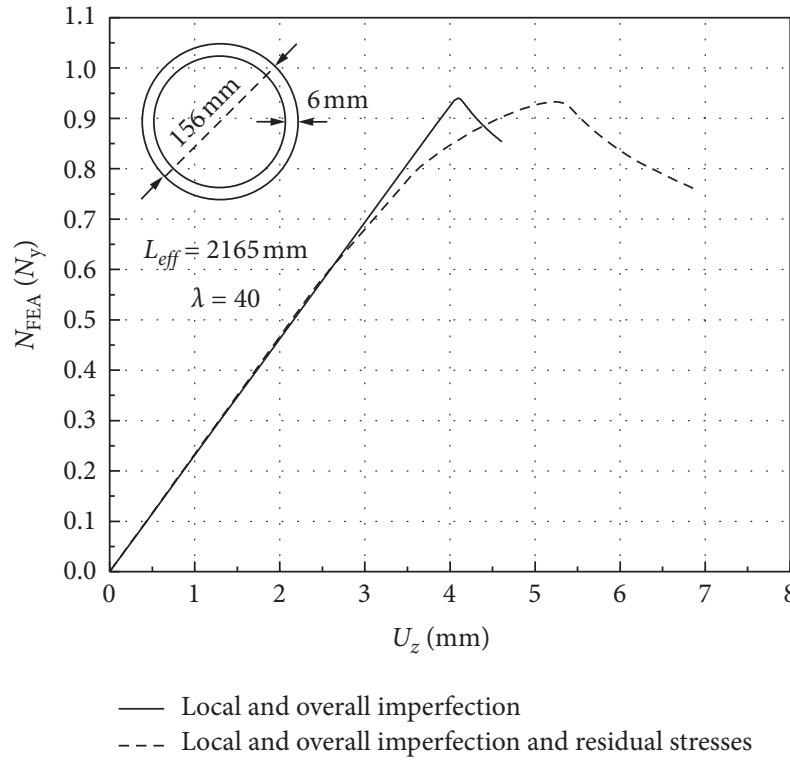

(a)

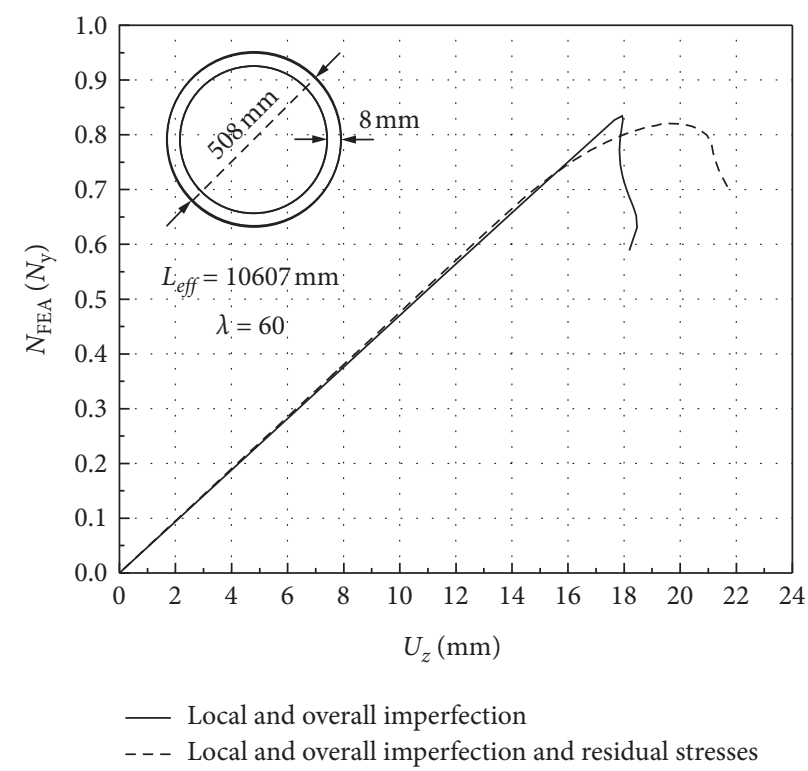

(b)

Figure 10: Comparison of load-axial deformation curve whether considering residual stresses. (a) D159 $\times 6(\lambda=40)$. (b) D508 $\times 8(\lambda=60)$.

characteristics, while, under the influence of the overall geometric imperfections, the ultimate capacity of the component decreased sharply after reaching its maximum value.

4.2. Effect of $D / t$ and Local Buckling Limits. $D / t$ is usually used to define the section classification and to judge whether the section can achieve full-section yield without buckling. In this section, the section of thin-walled steel circular tubes was mainly focused on. 30 FEMs with $D / t$ from 18 to 80 were calculated to elucidate the relationship between the ultimate capacity and $D / t$. The curve of $D / t$ versus the ultimate bearing capacity $P_{u} /\left(A f_{y}\right)$ is shown in Figure 13, including 3 test data (D420-20-1, D420-20-2, and D420-20-3) with local buckling failure in [1]. It is obvious that the bearing capacity decreased gradually resulting from larger $D / t$ and is smaller than the plastic bearing capacity of the full section, when $D / t$ exceeds a certain limit value, which is usually provided in the steel structure design specification, such as Eurocode 3 [16], AISC-360 [17], GB50017-2017 [2], ASCE48-05 [18], DL/ T5154-2012 [19], and AS4100 [20], the expression of which was shown in Table 5 . The comparison of the $D / t$ limit value 


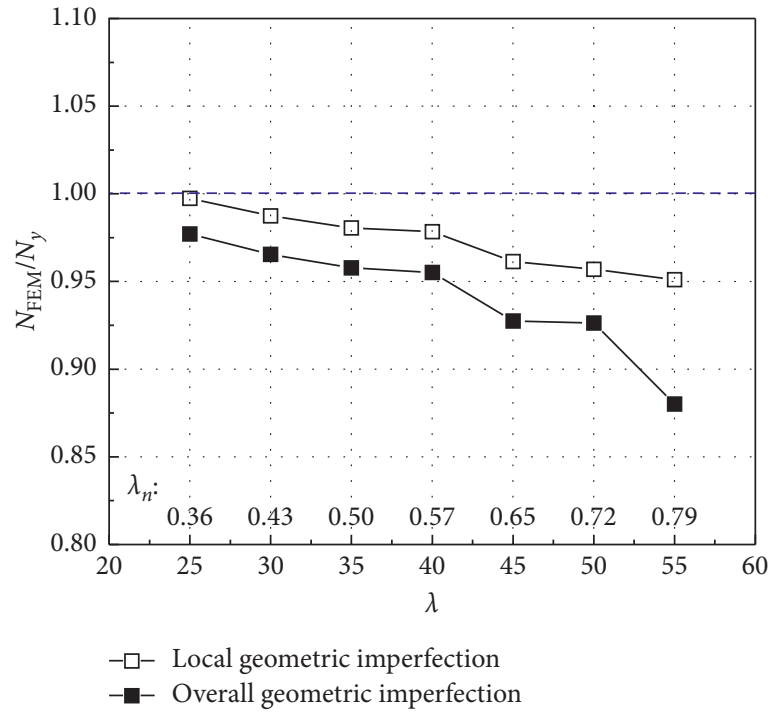

(a)

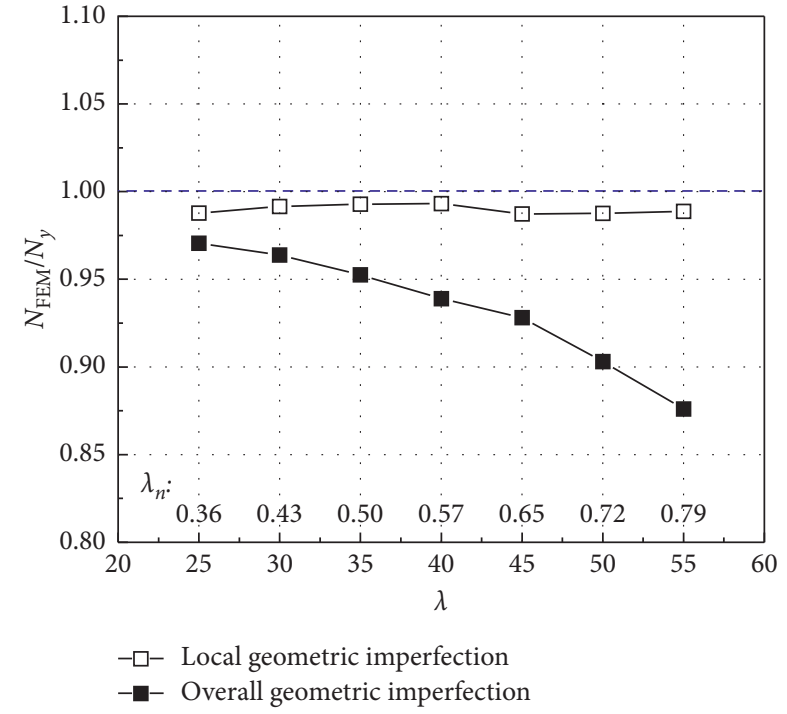

(b)

Figure 11: Comparison of geometric imperfection effect. (a) D159 $\times 6$. (b) D508 $\times 8$.

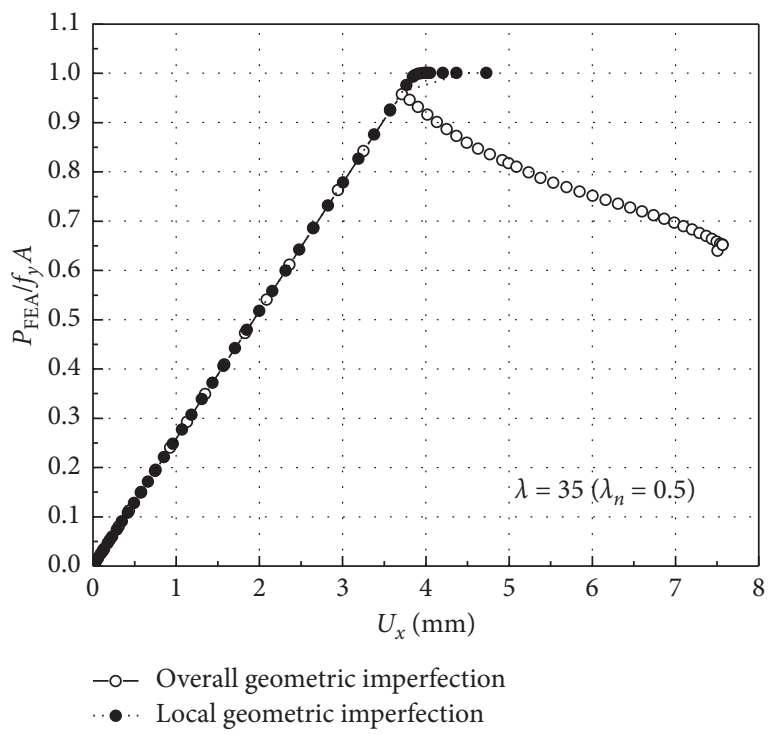

(a)

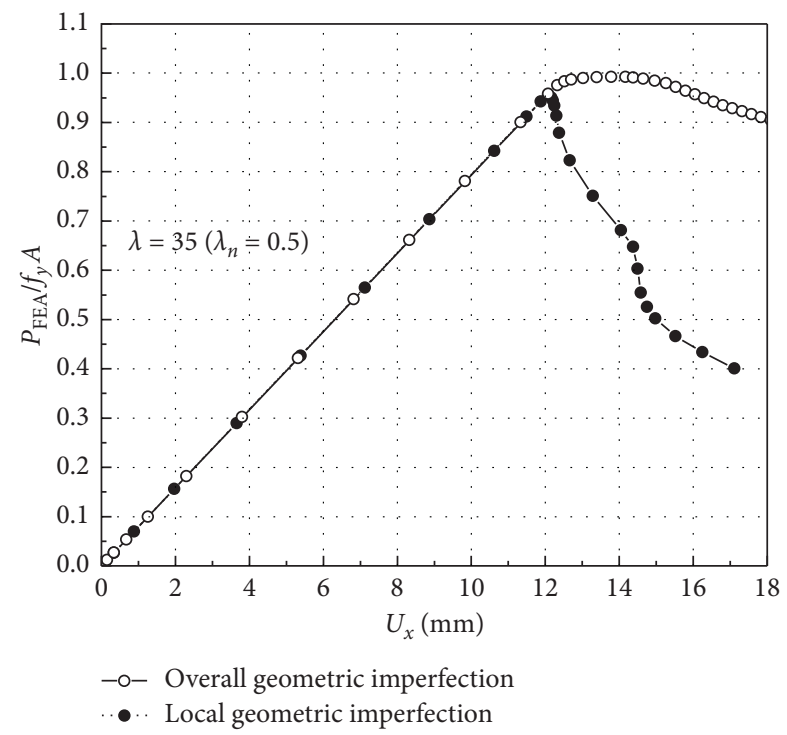

(b)

FIGURE 12: Comparison of load-axial deformation curves considering different geometric imperfections. (a) D159 $\times 6(\lambda=35)$. (b) D508 $\times 8$ $(\lambda=35)$.

for avoiding local bucking was conducted among the FEM results and the specification mentioned previously in Figure 13 marked $(D / t)_{\text {lim }}$. It is worth noting that the $D / t$ limit 27 for Q420 was far less than the value specified in the codes, mainly because, on the one hand, the mode of residual stresses and geometric amplitude applied on the FEMs were not always consistent in every research; on the other hand, when the section stresses exceeded the yield strength into the yield platform stage, the deformation modulus of the material changed to 0 , which weakened the section area significantly.
4.3. Development Path Tracking of Local-Overall Interactive Buckling. As proved in the test experiment, the overall-local interactive buckling occurred when slenderness ratio was in an intermediate range. In this section, two main issues were discussed: one was the failure process and the mode of localoverall buckling; the other one was the influence of slenderness $\lambda$ on the failure mode. By establishing the mapping path of the longitudinal FEA results (Figure 14), the deformation development states in the whole process of component failure were tracked. Figure 15 shows displacement curves of $\mathrm{D} 610 \times 8$ with slenderness ratio $\lambda=35$ 


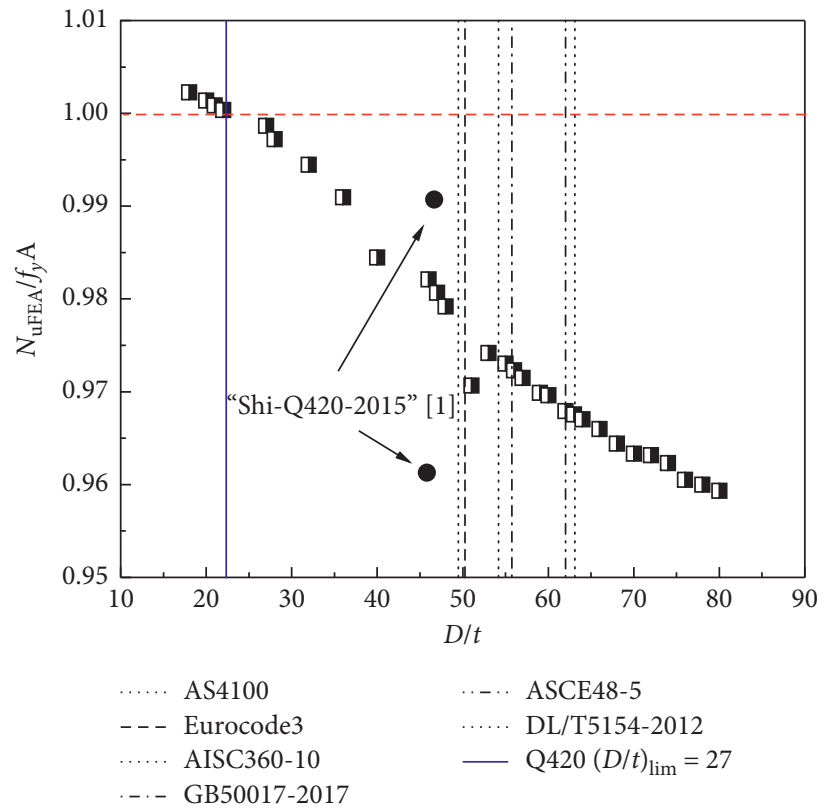

FIgURe 13: $D / t$ limit for local buckling.

Table 5: Existed local buckling limit for circular tubes.

\begin{tabular}{|c|c|c|c|c|c|c|}
\hline Limit criterion & & $D / t$ & & & $\lambda_{e}=\left((D / t) /\left(\sigma_{y} / 250\right)\right)$ & $\left(\left(E / \sigma_{y}\right) /(D / t)\right)$ \\
\hline Design code & $\begin{array}{c}\text { GB50017-2017 } \\
{[2]}\end{array}$ & $\begin{array}{c}\text { DL/T5154-2012 } \\
{[19]}\end{array}$ & $\begin{array}{c}\text { ASCE48-05 } \\
{[18]}\end{array}$ & $\begin{array}{c}\text { Eurocode } 3 \\
\text { [16] }\end{array}$ & AS4100 [20] & AISC 360-10 [17] \\
\hline Limit value & $100\left(235 / f_{y}\right)$ & $26775 / f_{y}$ & $26220 / f_{y}$ & $90\left(235 / f_{\mathrm{y}}\right)$ & 82 & $0.11 E / f_{y}$ \\
\hline $\begin{array}{l}\text { Equal to "GB50017- } \\
\text { 2017" }\end{array}$ & $100\left(235 / f_{\mathrm{y}}\right)$ & $113\left(235 / f_{\mathrm{y}}\right)$ & $111\left(235 / f_{\mathrm{y}}\right)$ & $90\left(235 / f_{\mathrm{y}}\right)$ & $87\left(235 / f_{\mathrm{y}}\right)$ & $97\left(235 / f_{\mathrm{y}}\right)$ \\
\hline Q420 & 55.95 & 63.22 & 62.11 & 50.36 & 48.68 & 54.27 \\
\hline
\end{tabular}

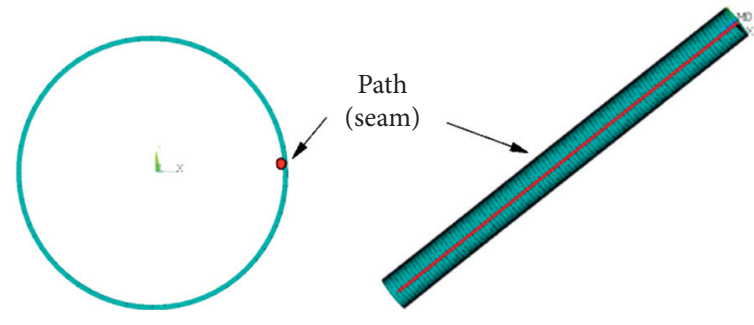

Figure 14: Mapping path of FEA results.

under axial loading, where $U_{z}$ represented the axial compression displacement at the end, $U_{x}$ represented the midspan transverse displacement in the $x$ direction, and P1 P5 were the state observation points.

The FEA results of $x$ direction displacement under P1 P5 load level were mapped to the path as shown in Figure 16, where it was observed that, in the initial stage of loading, the component was mainly characterized as overall bending deformation, when the ultimate load-bearing capacity was reached, local buckling appeared in the middle of the component, and the failure state of the column was characterized as local-overall interactive buckling.

The failure modes of columns with different slenderness ratio are given in Figure 17, where it was observed that when the slenderness ratio was 15 , the failure mode of the component was almost local buckling. When the slenderness ratio was less than 40 , the local buckling and overcall buckling were coupled, and when the slenderness ratio was greater than 40 , only the overall buckling was observed, which was consistent with the existing test law [1].

\section{Design Suggestion}

For the circular tube columns subjected to overall bending buckling, the ultimate capacity is expressed as

$$
N_{u}=\varphi A f_{y}
$$

where $\varphi$ is the overall buckling factor and $A$ is the gross area of circular tube. 


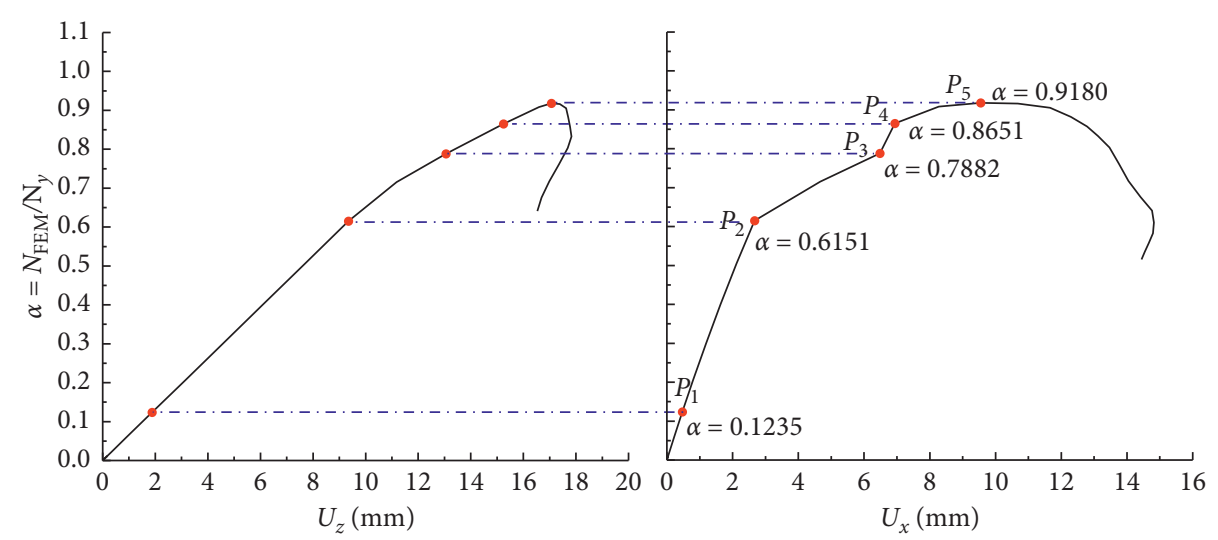

FIGURE 15: Load-displacement curves of D610 $\times 8(\lambda=35)$.
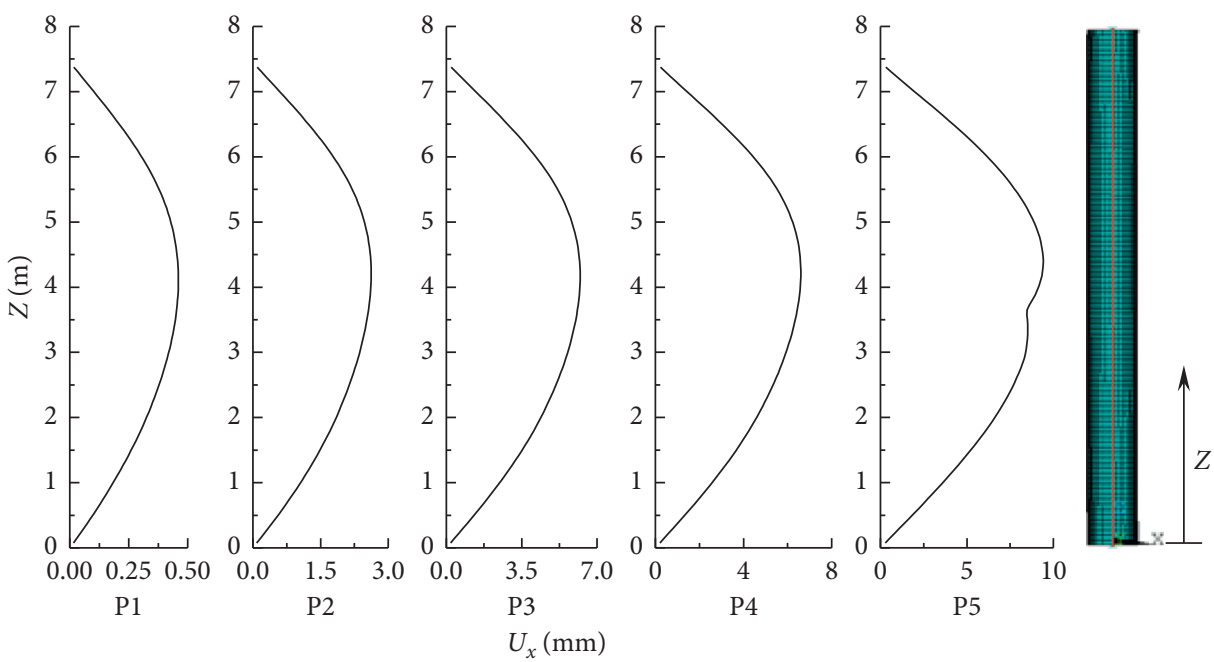

$U_{x}(\mathrm{~mm})$

Figure 16: D610 $\times 8(\lambda=35)$ deformation development under axial compression.
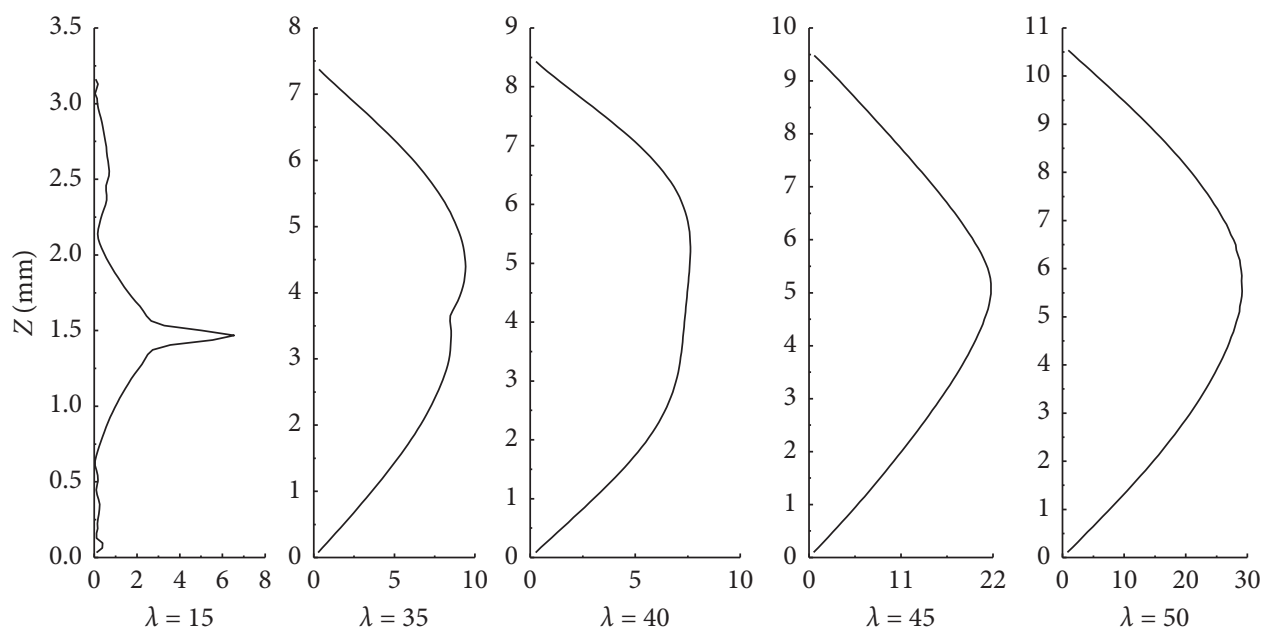

FIGURE 17: Failure mode (corresponding to P5) of D610 $\times 8$ with different slenderness. 
As for the local-overall interactive buckling, the section strength is influenced by the local buckling and the overall buckling coupling. The approach to separate the weight of the local buckling and the overall buckling coupling in the interactive buckling is to eliminate the influence of local buckling by stub column result and then to estimate the overall buckling performance through buckling factor $\varphi$. The details for the interactive buckling resistance can be expressed as (2) and (3) corresponding to the direct strength method (DSM) and effective width method (EWM), respectively. The two methods have some similarity; the former is through reducing the material strength $f y$ to reflect the local postbuckling strength, while the latter was to reduce cross-section area $A$. Combining (2) and (3) with (1), the approach to deal with interactive buckling of circular tube can be understood more clearly. One has

$$
N_{u}=\varphi A\left(f_{y} m_{n}\right),
$$

where $m_{n}$ is a strength reduction factor. One has

$$
N_{u}=\varphi(\rho A) f_{y}
$$

where $A_{\text {eff }}$ is an effective area mounted based on the effective width and $\rho$ is the ratio of $A_{\text {eff }}$ and $A$.

The strength reduction factor $m_{n}$ in (2) corresponding to DSM was discussed in Section 5.1.1. While (3) represents that the effective width of the circular tube is used to reflect the weight of local buckling in the interactive buckling, which was discussed in Section 5.1.2.

5.1. Local Postbuckling Strength. The ultimate capacity of stub columns is mainly restricted by the local buckling capacity. In this section, $m_{n}$ used in DSM and $\rho$ used in EWM were discussed in detail to estimate the local postbuckling strength quantitatively. The applicability of provision in DL/T 5154-2002 [19], ASCE/SEI 48-05 [18], and AS4100 [20] based on DSM and EWM, respectively, for local postbuckling strength was validated based on the test data and analysis of FE models.

5.1.1. Direct Strength Method. The concept of direct strength method (DSM) is to multiply the material strength $f y$ by the reduction factor $m_{n}$ to reflect the effect of local buckling on material strength expressed as

$$
m_{n}=\frac{N_{u}}{A f_{y}},
$$

where $N_{u}$ is the ultimate capacity of stub columns and $A$ is cross-section area. Based on the FE model result, according to (4), the strength reduction factor $m_{n}$ was derived. The comparisons of $\mathrm{FE}$ analysis results with the curves according to DL/T5154-2012 [19] (see (5)), ASCE48-05 [18] (see (6)), and test data in [1] were carried out, as shown in Figure 18. It can be seen that when $D / t$ was in the range from 23 to 72 , test results and the FEM results were both smaller than those of the codes. Taking test data D420-20-1 as an example, $m_{n}$ of experiment data 0.968 was $1.7 \%$ smaller than that of FEM

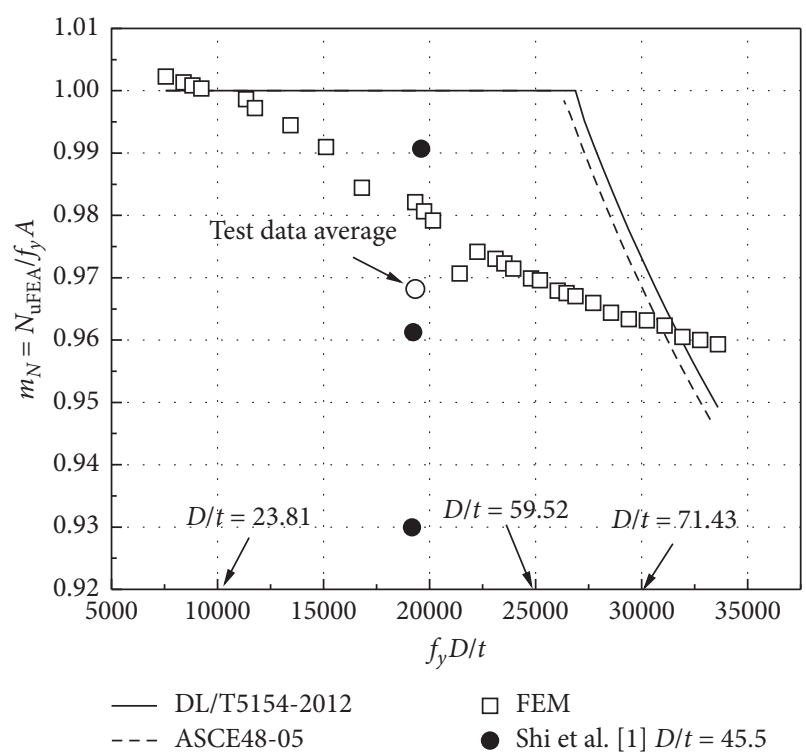

FIgURE 18: Strength reduction factor $m n$ versus $f y D / t$.

and 3.2\% smaller than that of DL/T5154-2012 and ASCE4805 . According to the rule reflected in Figure 18, it can be predicted that FEM result would exceed the existing codes, resulting from larger $D / t$. Design results from ASCE48-05 and DL/T5154-2012 overestimated the local postbuckling strength basically, when $D / t$ was in the range from 23 to 71 discussed in this work, but underestimated it when $D / t$ was larger. One has

$$
m_{n}= \begin{cases}1 ; & \frac{D}{t} \leq \frac{24100}{f_{y} / 1.111}, \\ 0.75+\frac{6050}{(D / t) f_{y} / 1.111} ; & \frac{24100}{f_{y} / 1.111} \leq \frac{D}{t} \leq \frac{24100}{f_{y} / 1.111},\end{cases}
$$

where $m_{n}$ is the strength reduction factor and $f_{y}$ is steel yield strength. One has

$$
m_{n}= \begin{cases}1 ; & \frac{D}{t} \leq \frac{3800 \Phi}{f_{y}}, \\ 0.75+\frac{950 \Phi}{f_{y} D / t} ; & \frac{3800 \Phi}{f_{y}} \leq \frac{D}{t} \leq \frac{12000 \Phi}{f_{y}} .\end{cases}
$$

When the unit of $f_{y}$ and $F_{a}$ is MPa, $\Phi$ is adopted as 6.9.

5.1.2. Effective Width Method. Due to the influence of residual stresses and geometric initial imperfections, the stresses in part of the section exceed the yield strength firstly and are not considered to resist the external load. Therefore, the EWM deems that the stress along the imaginal part of the circumference (equivalent diameter $D_{e}$ ) reached $f_{y}$, ignoring the buckled area, and the area reduction factor $\rho$ can be expressed as 


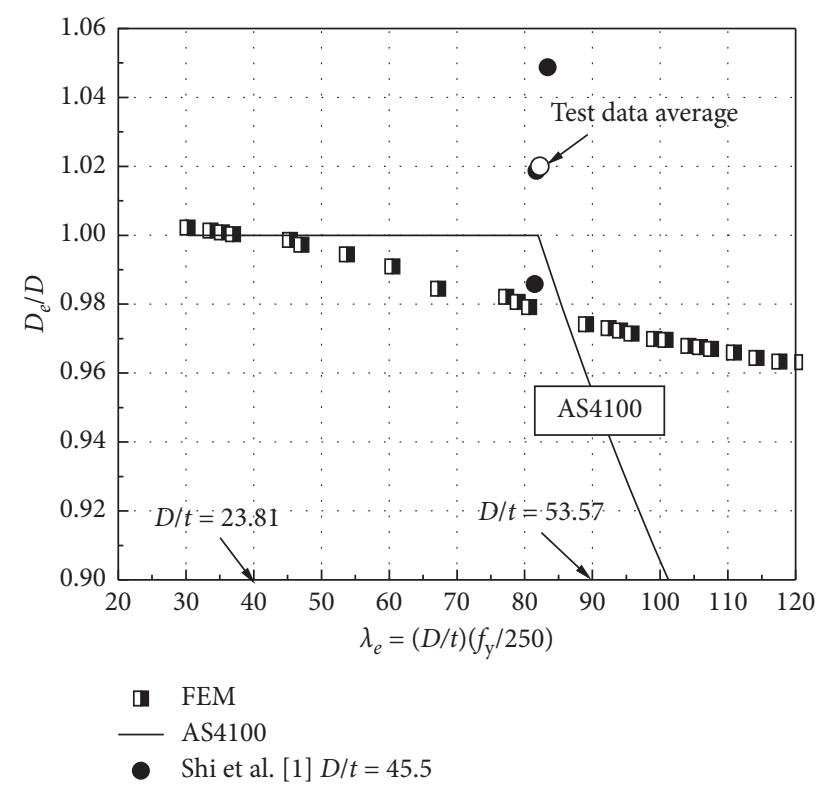

FIgURE 19: Effective diameter $D_{e}$ versus $\lambda$.

$$
\rho=\frac{N_{u}}{A f_{y}}=\frac{A_{e f f}}{A}=\frac{\pi}{4}\left(\frac{D_{e}}{D}\right)^{2} .
$$

Based on the FE model result, according to (7), the equivalent diameter $D_{\mathrm{e}}$ was derived. The comparison of the ratio of $D_{e} / D$ versus nondimensional slenderness $\lambda_{e}$ of FEM, AS4100 (expressed as (8)), and test data in [1] is depicted in Figure 19. It can be seen that the result of AS4100 was larger than that of FEM for the case of $D / t$ between 23 and 53 and obviously decreased, when $D / t$ was between other complementary ranges. Taking $\lambda_{e}=80(D / t=47.62)$ as an example, AS4100 was 2.1\% larger than FEM and about $2 \%$ smaller than test data in [1]. Generally, design results from AS4100 overestimated the postbuckling strength, when $D / t$ was in the range from 23 to 53 discussed in this work, but underestimated it when $D / t$ was larger. One has

$$
\left\{\begin{array}{l}
D_{e}=D \sqrt{\left(\frac{\lambda_{e y}}{\lambda_{e}}\right)} \leq D ; \\
D_{e}=D\left(\frac{3 \lambda_{e y}}{\lambda_{e}}\right)^{2} ; \\
\lambda_{e y}=82 \\
\lambda_{e}=\frac{D}{t} \frac{f_{y}}{250} .
\end{array}\right.
$$

5.2. Buckling $\varphi$ Research. Based on the results discussed in Section 5.1, the local buckling weight can be stripped out from the interactive buckling effect. The buckling factor $\varphi$ can be expressed as (9) and (10) derived from (2) with (3) to estimate overall bending weight in the interactive buckling. One has

$$
\begin{aligned}
& \varphi=\frac{N_{u}}{A\left(m_{n} f_{y}\right)}, \\
& \varphi=\frac{N_{u}}{A_{\text {eff }} f_{y}}=\frac{N_{u}}{(\rho A) f_{y}} .
\end{aligned}
$$

In GB50017-2017, curve b was adopted to design welded tubular section columns. According to (9) and (10), the overall buckling factor $\varphi$ of FEM, test [1], and GB50017-2017 is depicted in Figures 20(a) and 20(b), excluding the effect of the local buckling using the provision in ASCE48-05 (DSM) and AS4100 (EWM), respectively. In Figure 20(a), it can be seen that when $\lambda_{n}\left(\lambda_{n}=\left(\lambda_{l} / \pi\right) \sqrt{f_{y} / E}\right)$ smaller than $0.6, \varphi$ of FEM was closer to curve a in GB50017-2017, while exceeding 0.6 , smaller than curve a. On average, $\varphi$ of FEM was $2.79 \%$ and $12.41 \%$ larger than curve a and curve b in GB500172017, respectively. In Figure 20(b) corresponding to the case of excluding the local buckling effect by the provision in AS4100, it can be observed that, for the sections with the $D / t$ exceeding the limit, $\varphi$ was obviously larger than curve a in GB50017-2017 and the data was discrete to some extent.

In Eurocode3, curve c was adopted to design welded tubular section columns (or cold-formed tubular sections). According to (9) and (10), the overall buckling factor $\varphi$ of FEM, test [1], and Eurocode 3 is depicted in Figures 21(a) and $21(\mathrm{~b})$, considering the effect of the local buckling using the provision in ASCE48-05 (DSM) and AS4100 (EWM), respectively. From Figure 21(a), it can be obtained that both the test data and the FEM results show that it was more reasonable to choose curve a of Eurocode 3 as the overall buckling factor $\varphi$ for circular tube of Q420, which was $1.27 \%$ larger than FEM result on average. In Figure 21(b), from the local buckling effect distinguished according to AS4100, the FEM data still showed obvious discreteness and was larger than curve a in Eurocode3. 


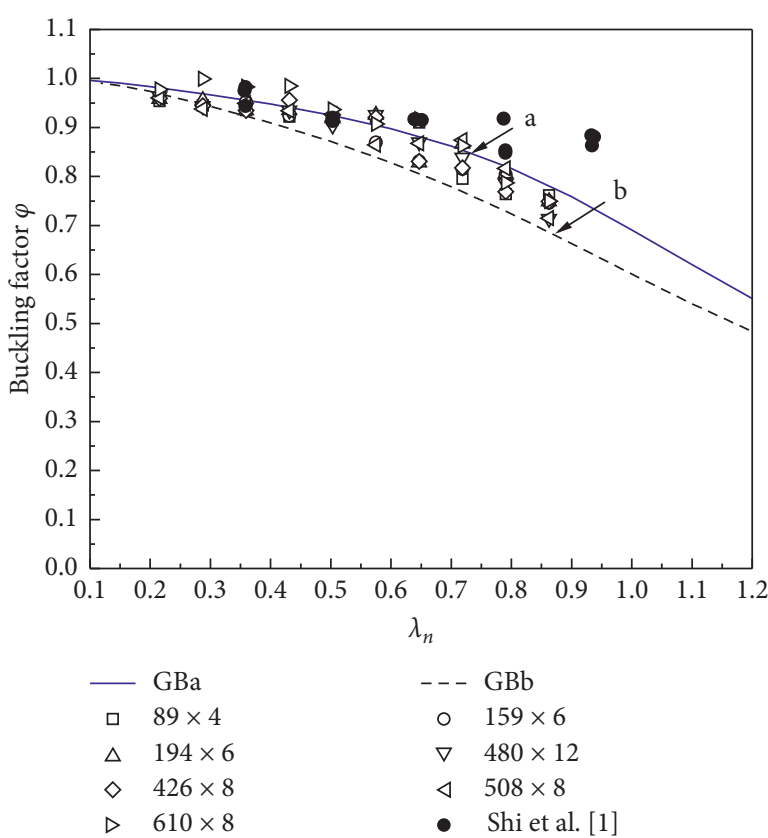

(a)

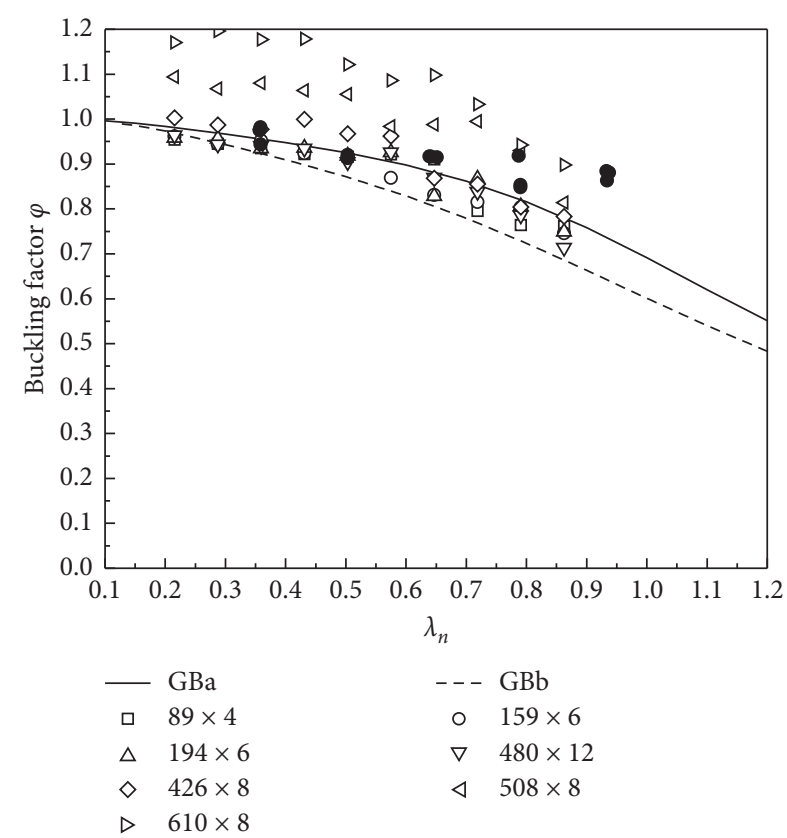

(b)

FIGURE 20: Comparison of FEM results with design curve GB50017-2017. (a) Excluding the local buckling effect with a provision in ASCE4805. (b) Excluding the local buckling effect with a provision in AS4100.

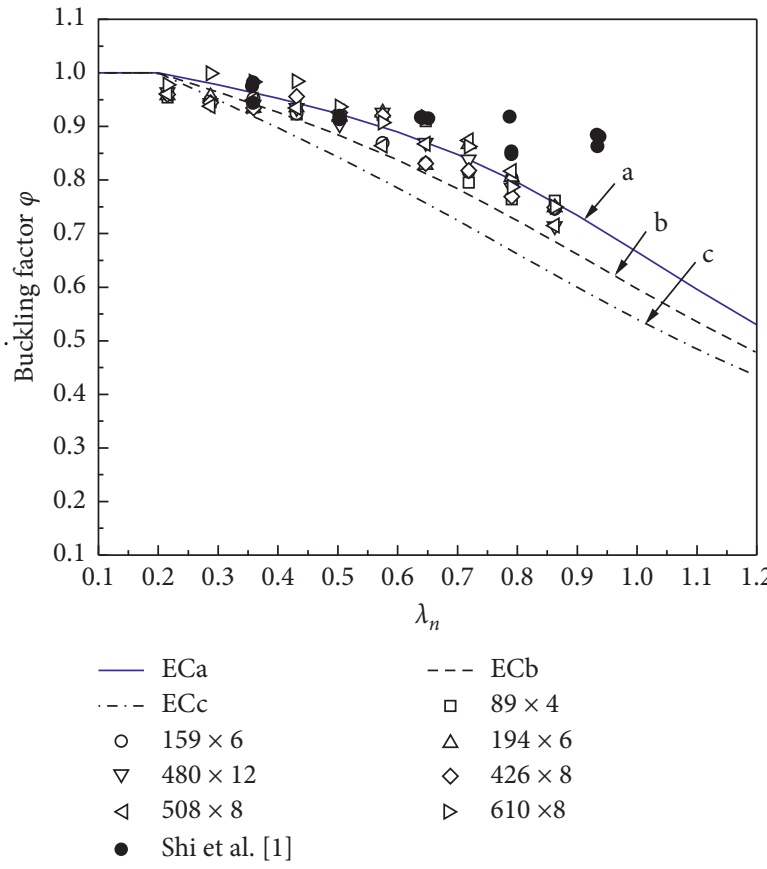

(a)

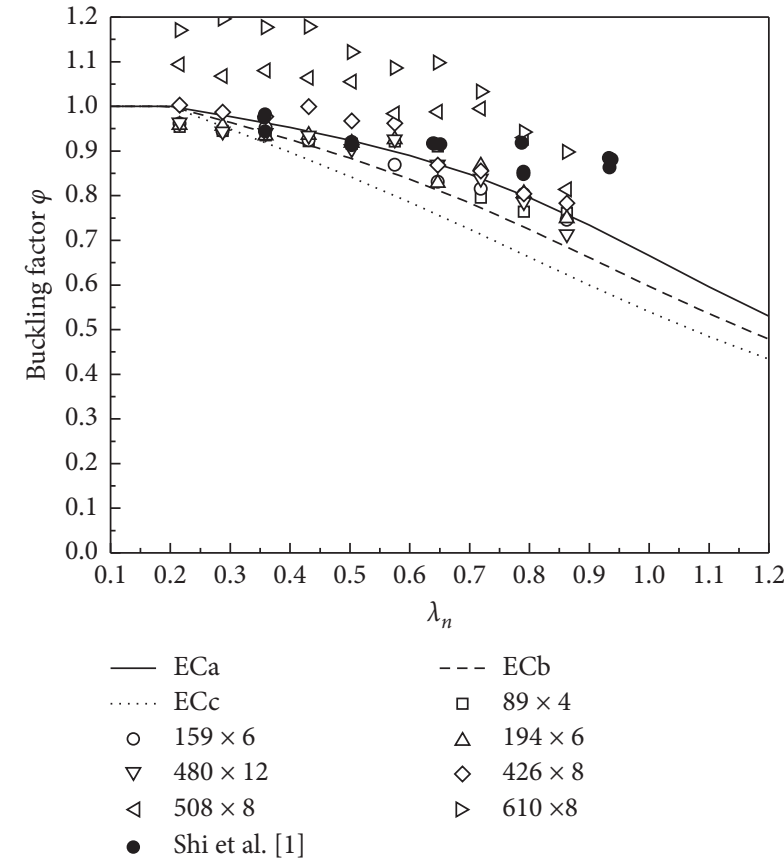

(b)

FIGURE 21: Comparison of FEM results with design curve Eurocode 3. (a) Excluding the local buckling effect with a provision in ASCE48-05. (b) Excluding the local buckling effect with a provision in AS4100.

\section{Conclusion}

This work provided an investigation on local-overall buckling of Q420 welded circular tubes under axial compression. With validated FEMs, the influence of residual stresses and geometric imperfection on bearing capacity was investigated and failure process and failure mode of interactive buckling of Q420 welded circular tubes were studied. Based on the test 
data and FEM results, the approach to estimate the interactive buckling using DSM and EWM was proposed, respectively. The conclusions of this paper are as follows:

(1) The effect of residual stresses varies with the slenderness ratio of components; the bearing capacity of members with medium length can be reduced up to $11.8 \%$. Based on the research on geometric imperfection, when the overall slenderness ratio is exceeding 25, the influence of overall geometric defects plays a major role compared with that of local geometric imperfection, which leads to the reduction of ultimate capacity up to $11.5 \%$.

(2) For the Q420 welded circular tube, the $D / t$ limit value for local buckling was 27, smaller than the values given in corresponding codes. The slenderness limit 40 was proposed to distinguish whether the local buckling was considered.

(3) The local buckling resistance according to the ASCE48-05 and AS4100 was slightly larger than the FEM result with $D / t$ in the range from 23 to 71 and from 23 to 53, respectively, while it became smaller for larger $D / t$.

(4) Based on the existing data and FE model result, the design curve a in both GB50017-2017 and Eurocode 3 was recommend to be used in the estimated interactive buckling resistance of Q420 welded circular tubes according to (9) and (10) corresponding to DSM and EWM, respectively. In addition, more experimental and numerical investigations are of course needed to further confirm the conclusions obtained in this paper.

\section{Data Availability}

The data used to support the findings of this study are available from the corresponding author upon request.

\section{Disclosure}

Any opinions, findings, conclusions, and recommendations presented in this paper are from the writers and do not necessarily reflect the views of the sponsors.

\section{Conflicts of Interest}

The authors declare that they have no conflicts of interest.

\section{Acknowledgments}

This work was financially supported by the Natural Science Foundation of Jiangsu Province (Grant no. BK20191013) and Scientific Research Foundation of Nanjing Institute of Technology under Grant no.YKJ201837. All sponsors were gratefully acknowledged.

\section{References}

[1] G. Shi, X. Jiang, W. Zhou, T.-M. Chan, and Y. Zhang, "Experimental study on column buckling of $420 \mathrm{MPa}$ high strength steel welded circular tubes," Journal of Constructional Steel Research, vol. 100, pp. 71-81, 2014.

[2] GB 50017-2017, Code for Design of Steel Structures, China Architecture \& Building Press, Beijing, China, 2018.

[3] H. Schmidt and T. H. A. Winterstetter, "Cylindrical shells under combined loading: axial compression, external pressure and membrane shear," in Buckling of thin metal Shells, J. G. Teng and J. M. Rotter, Eds., vol. 38pp. 476-584, 2001.

[4] T. A. Winterstetter and H. Schmidt, "Stability of circular cylindrical steel shells under combined loading," Thin-Walled Structures, vol. 40, no. 10, pp. 893-910, 2002.

[5] X.-L. Zhao, "Section capacity of very high strength (VHS) circular tubes under compression," Thin-Walled Structures, vol. 37, no. 3, pp. 223-240, 2000.

[6] H. Jiao and X. L. Zhao, "Imperfection residual stress and yield slenderness limit of very high strength VHS circular steel tubes," Journal of Constructional Steel Research, vol. 59, pp. 233-249, 2013.

[7] Z. Y. Shen, Y. Y. Chen, X. C. Chen, and X. Q. Xiao, Study Tubular on the Overall Steel Columns and Local Instability of under Axial Compression, Shanghai LiXue, Shanghai, China, 1988, in Chinese.

[8] W. L. Wagner, W. H. Mueller, and H. Erzurumlu, "Design interaction curves for tubular steel beam-columns," Journal of Petroleum Technology, vol. 30, no. 3, pp. 367-373, 1978.

[9] W. F. Chen and D. A. Ross, "Test of fabricated tubular columns," Journal of the Structural Division, vol. 103, no. 3, pp. 619-634, 1977.

[10] G. Shi, X. Jiang, W. Zhou, T.-M. Chan, and Y. Zhang, "Experimental investigation and modeling on residual stress of welded steel circular tubes," International Journal of Steel Structures, vol. 13, no. 3, pp. 495-508, 2013.

[11] J. F. Yang, X. F. Yan, H. F. Liu, J. P. Cheng, and Y. H. Zhan, "Detection and analysis on residual stress distribution induced by the processing method of circular tubes," Engineering Mechanics, vol. 34, no. 9, pp. 202-210, 2017.

[12] H. Wang, Y. H. Guo, Y. T. Bai, B. Zhang, Q. Sun, and J. Y. Xue, "Experimental and numerical study on the stability capacity of Q690 high-strength circular steel tubes under axial compression," International Journal of Steel Structures, vol. 17, no. 3, pp. 843-861, 2017.

[13] X. F. Yan and C. Yang, "Experimental research and analysis on residual stress distribution of circular steel tubes with different processing techniques," Thin-Walled Structures, vol. 144, pp. 1-12, 2019.

[14] S. M. Chou, G. B. Chai, and L. Ling, "Finite element technique for design of stub columns," Thin-Walled Structures, vol. 37, no. 2, pp. 97-112, 2000.

[15] H. Y. Ban, G. Shi, Y. J. Shi, and Y. Q. Wang, "Research advances on mechanical properties of high strength structural steels," Building Structure, vol. 43, no. 2, pp. 88-94, 2013.

[16] BS EN1993-1-1, "Eurocode 3:design of steel structure, part 1-1:general rules and rules for buildings," 2005.

[17] ANSI/AISC 360-16, Specification for Structural Steel Buildings, American Institute of Steel Construction, Chicago, IL, USA, 2016.

[18] ASCE/SEI 48-05, Design of Steel Transmission Pole Structures, American Society of Civil Engineers, New York, NY, USA, 2005.

[19] DL/T 5154-2002, Technical Regulations for Tower Structure Design of Overhead Transmission Lines, China Construction Industry Press, Beijing, China, 2012, in Chinese.

[20] Australian Standard (AS), AS 4100-1998, Steel Structures, Standards Australia Limited, Sydney, Australia, 2012. 